\title{
The simulation model for a flood management by flood control facilities
}

\author{
Roman Davydov ${ }^{1, *}$, Valery Antonov ${ }^{1}$, Dmitry $_{\text {Molodtsov }}{ }^{1}$, Alexey Cheremisin ${ }^{1}$, and Vadim \\ Korablev $^{1}$ \\ ${ }^{1}$ Peter the Great St. Petersburg Polytechnic University, Polytechnicheskaya 29, St. Petersburg, \\ 195251, Russian Federation
}

\begin{abstract}
The rapid spread of storm floods over large areas requires flood management throughout the river basin by the creation an innovative system of flood control facilities of various functional purposes distributed in the area. The central part of the system is the hydro system with hydro power plant. In addition, the flood control facilities on the side tributaries with self-regulating reservoir are included in the system. To assess the effect of controlling extreme water discharges by flood control facilities, it is necessary to develop special mathematical models reflecting the specifics of their operation. Unified mathematical models of the operation modes of a hydro complex with hydroelectric power station and flood control facility are created. They are implemented in a computer program that provides the ability to determine the main parameters and operating characteristics of hydro systems when performing multivariate calculations in a wide range of initial data. This makes possible specifying the parameters and operation modes of each hydro system with the current economic and environmental requirements, to assess the energy-economic and environmental consequences in the operation of the system of flood control facilities distributed in the area. The article analyses the results of the extreme water discharge's regulation by the hydro system on the main river and flood control facilities on the side tributaries, considering environmental requirements.
\end{abstract}

\section{Introduction}

Nowadays, in the conditions of the observed trend of global climate changes [1-3] and, consequently, changes in the river flow [4-6] an issue of flood management is acute, which requires a new approach of using hydroelectric power plant (HPP) in the flood situation [611]. Heavy and long duration floods are dangerous for the population, economic activity and nature since they cover large areas, leading to a large loss of life and huge economic and environmental damage [12]. Therefore, there is a need for additional research [13-17], for improving the methods of environmental monitoring [18-23] and flood management strategy.

\footnotetext{
* Corresponding author: davydovroman@ outlook.com
} 
The task is complicated by the fact that in order to reduce land flooding in the practice of hydropower construction in recent years [24-28], preference has been given to the construction of hydro systems with a relatively small capacity of the reservoir and, consequently, with a reduced possibility of regulating river flow. In these conditions, the necessary additional regulating capacity is proposed to be placed on side tributaries of a river, creating flood control facilities with uncontrolled bottom and surface spillways.

The object of the research is the creation an innovative system for managing extreme water discharges in a river basin by hydro systems on the main river and hydro systems with self-regulating reservoirs distributed on the river's side tributaries. This will provide flood control throughout the river basin and minimize the damage during the floods [29, 30].

The tasks of the research are the improvement of the models of flow management in the river basin. This makes possible determining the operating modes of hydro systems of various purposes (single small flood control facility or hydro complex with hydroelectric power plant) under conditions of asynchronous extreme discharges in the water system and clarify the parameters of flood control facilities. The following mathematical models have been developed [31, 32]:

- The mathematical model of extreme flow management by flood control facilities,

- The mathematical model of operating modes of a hydro complex with a HPP,

- The integrated river flow management model of a system of flood control facilities distributed on a drainage basin.

To accomplish the tasks of the research, it was necessary to create a computer program for performing automated calculations of river flow regulated by a system of flood control facilities distributed in the area. It makes possible performing large amount of calculations, which are necessary to select and justify the scheme of flood control facilities for the specific river basin, as well as to determine their parameters and operating modes, considering modern economic and environmental requirements, assessing the energyeconomic and environmental effect.

\section{Methods}

The example scheme of a system of flood control facilities distributed on a drainage basin is presented in Fig. 1. Here:

1) The hydrograph of extreme natural water flow with $1 \%$ probability of the main river,

2) The hydrograph of managed water flow in the lower pool of the hydro complex with the designed maximum water level,

3) The hydrograph of managed water flow in the lower pool of the hydro complex with the reduced maximum water level considering the current and prospective environmental and economic conditions,

4) The hydrograph of extreme natural water flow with $1 \%$ probability of the side tributary,

5) The hydrograph of managed water flow in the lower pool of the flood control facility of the side tributary, which accepts the missing volume for flood control from the main reservoir,

6) The hydrograph of managed water flow in the lower pool of the hydro complex under the reducing extreme water flow on the side tributaries, where $Q_{\max }$ - the maximum allowable river flow. 


\section{EECE-2018}

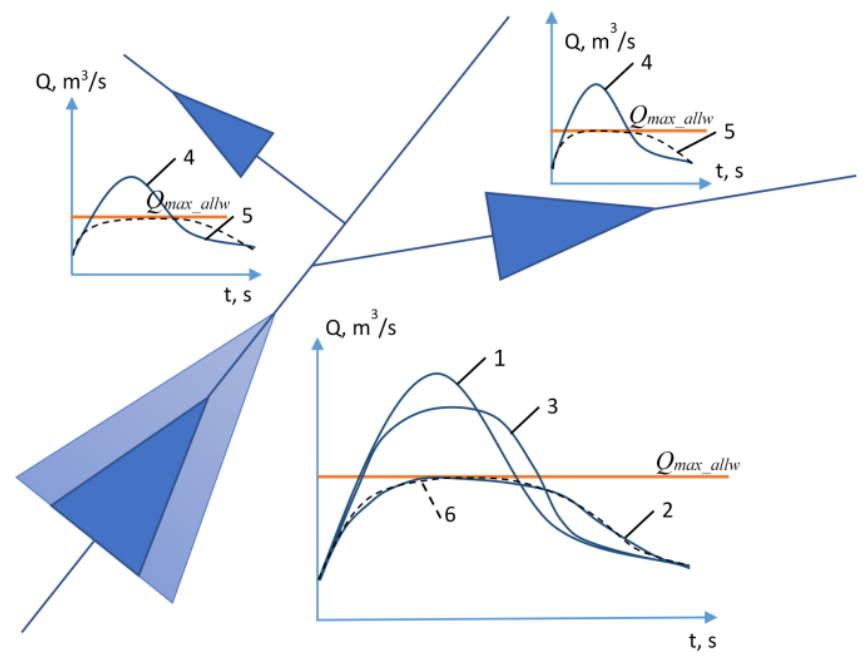

Fig. 1. The scheme of a system of flood control facilities distributed on a drainage basin.

The developed mathematical models are implemented in the form of the computer program written in Matlab language with a graphical interface for a personal computer. This program performs calculations on various initial data (which can be putted manually or loaded from files), display the results on the screen and save the calculation results (fully or selectively) into files - Microsoft Excel format for further processing in other applications (including geographic information systems (GIS)) and graphic formats (bmp, jpeg, tiff) for plots.

The user interface for calculating the parameters and operating modes of flood control facilities on the side tributaries is shown in Fig. 2.

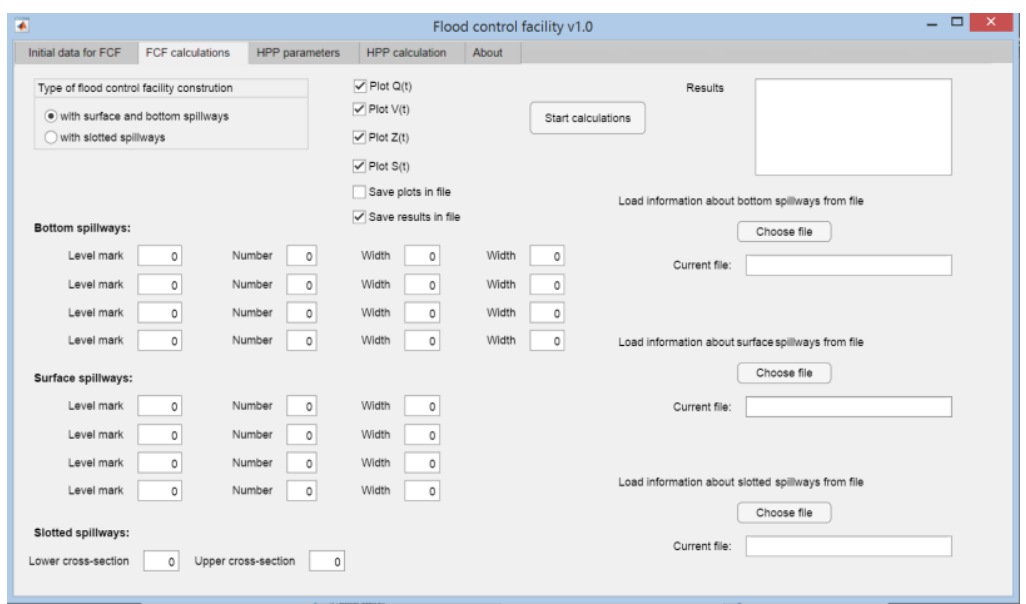

Fig. 2. The computer program interface.

In this program the simulation of the flood control facility operating modes for various constructions (with surface, bottom and slotted spillways) can be conducted. In addition, it is possible to justify the parameters of the flood control facility (maximum allowable level of the upper pool, number of spillways, their sizes, etc.) to minimize the area of land flooding and preserve biodiversity of ecosystems. The results of calculations in this program are further used: 
- For calculating the operation modes of a complex hydro system with a hydroelectric power station on the main river, while regulating extreme river discharges, considering the joint work with flood control facilities on the side tributaries,

- To visualize areas of flooding on the map and assess environmental and economic consequences using GIS,

- To model the ecological situation in the impact zone of the flood control facility (assessment of the safety of natural systems, the quality of the water in the downstream, etc. during short-term flooding, depending on the duration of flooding, water level, etc.).

Moreover, this program has a part associated with flow management of a hydro complex with a HPP at the following stages:

- The period of reservoir filling,

- The period of accumulation of flood flows,

- The period of reservoir draw-off.

There are a lot of changeable parameters for calculations, associated with hydrology (initial water level marks and maximum allowable, water flows, requirements of water consumption users, etc.) and operation (power, number of aggregates, average annual power generation, operational characteristics of hydraulic turbines, project dispatch schedule, restrictions on frequency of operations on opening / closing of spillways, etc.).

The results of calculations in this program are further used:

- To adjust the design marks of the Maximum Water Level (MWL), considering existing and prospective socio-economic and environmental conditions.

- For calculating the operation modes of HPPs on the main river when regulating extreme river runoff, considering the joint work with flood control facilities on the side tributaries.

- To visualize areas of flooding on the map and assess environmental and economic consequences using GIS.

- To model the ecological situation in the upper and lower pool of the complex hydroelectric complex with HPP.

\section{Results and discussion}

Using the developed program suite, the simulation of the operating modes of the flood control facilities in the basin of one of the rivers in the Far Eastern region of Russia, where the largest rise in the water level is observed as a result of intense rain flooding, has been carried out. Fig. 3 shows the results of calculations for the management of extreme water discharges by the flood control facility with various automatically tested sets of parameters. Fig. 4 shows the change in water levels in the upper pool of the flood control facility.

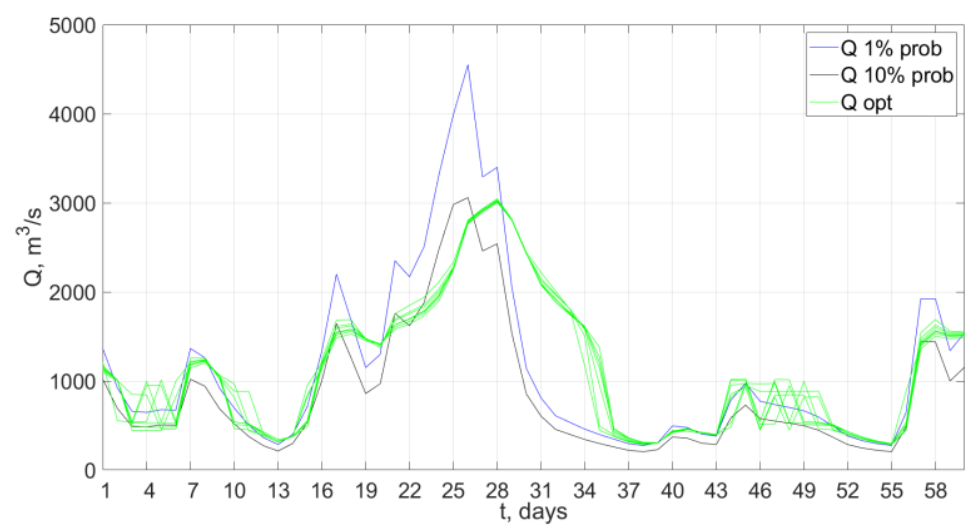

Fig. 3. The regulated water discharges in the lower pool of the flood control facility. 


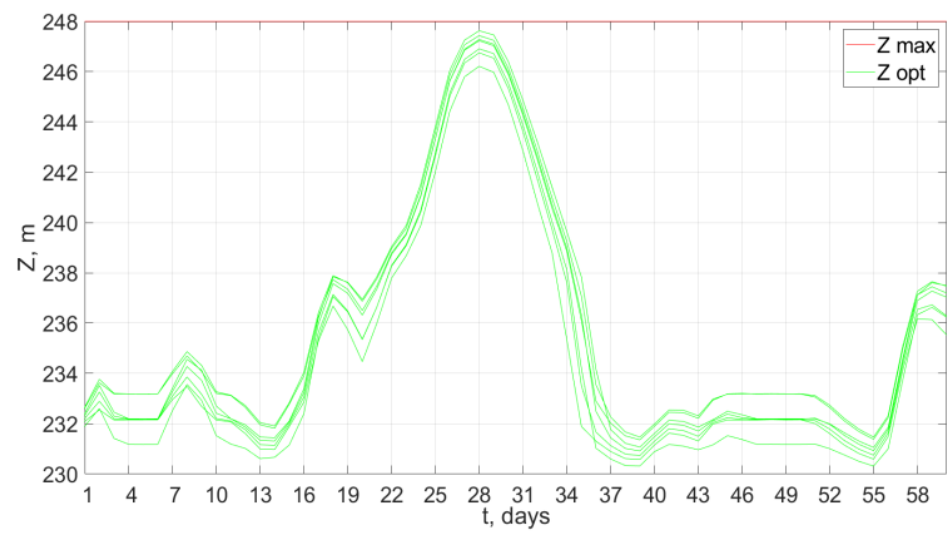

Fig. 4. The water level changes in the upper pool of the flood control facility during the accumulation of extreme water discharges.

The results of calculations of the hydro complex operating modes with a HPP in a highwater year with accumulation of water discharges during the year are presented in Fig. 5 . Test calculations of the joint operation of the hydro complex with HPP and with one of the largest flood control facility on a side tributary of the river showed that the extreme consumption of water entering the reservoir on the main river is reduced by about $10 \%$. At the same time, the regulated water discharges in the lower pool can be reduced by $30 \%$ as compared with the natural water discharge with probability of 1\% (Fig. 6).

The developed models make it possible to refine the mark of the MWL of the hydro complex, considering the possible economic and ecological situation in the upper pool. If, as a result of the economic development of the territories, it is necessary to lower the mark of the MWL, then calculations are made and the appropriate parameters of the flood control facilities are selected. As an example, the situation when the maximum water level is reduced by 1 meter is studied, respectively, the flooded area in the upper pool of the hydro complex decreases by $13 \%$. In this case, the missing storage capacity is placed in the flood control facility on the side river tributary (Fig. 7).

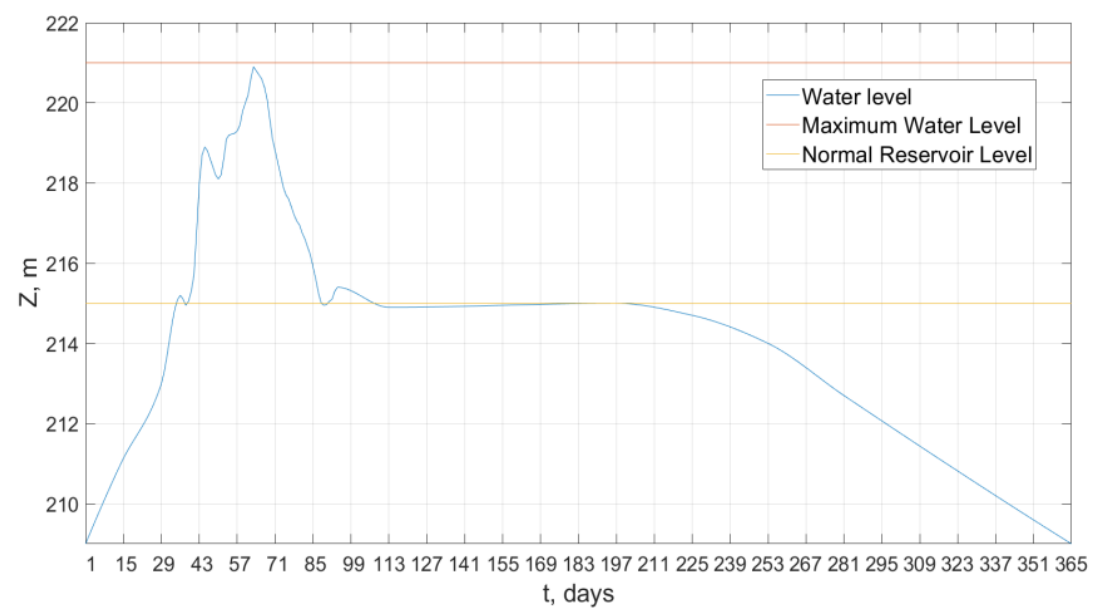

Fig. 5. The water level in the upper pool of the hydro complex with the HPP (with using flood control facility on the side tributary) during the year. 


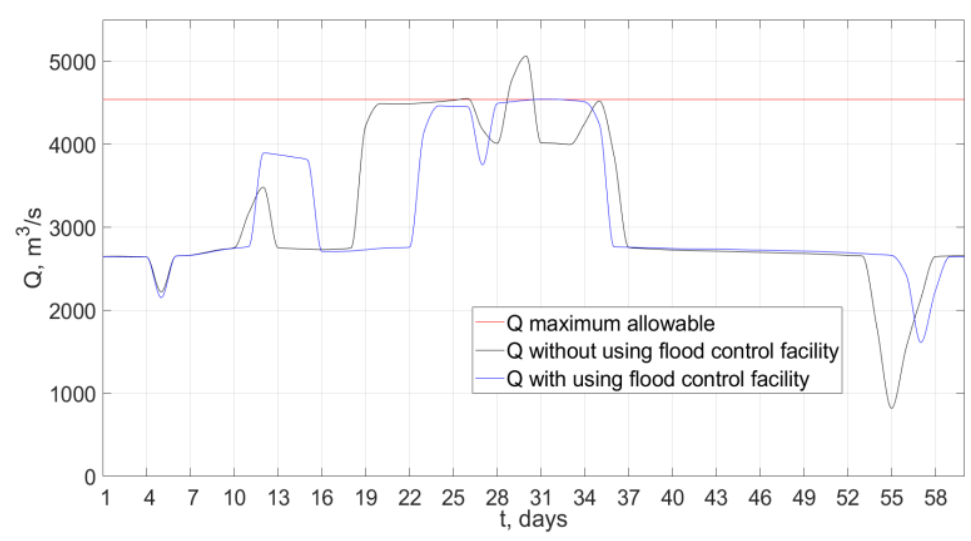

Fig. 6. The regulated water discharges in the lower pool with and without using flood control facility on the side tributary.

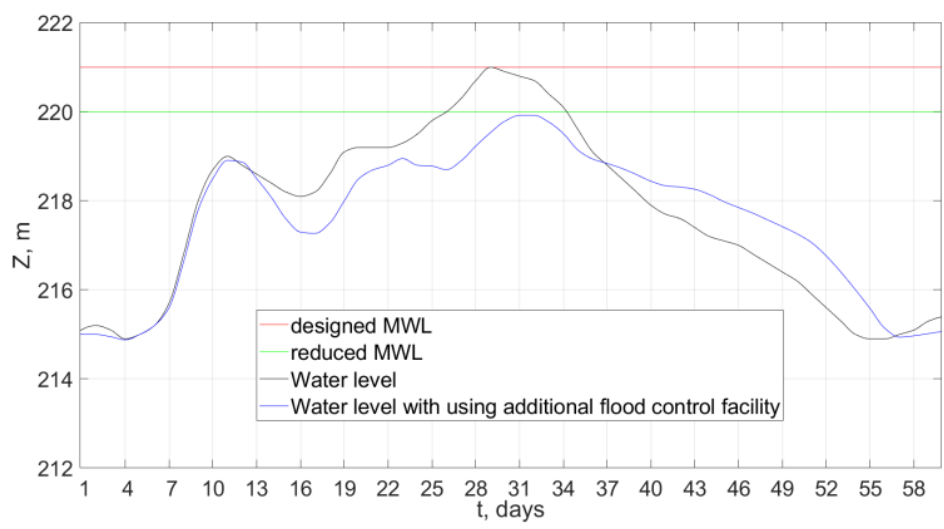

Fig. 7. The water level in the upper pool of the hydro complex with the HPP with and without using additional flood control facility on the side tributary.

The results for the hydro systems obtained in the computer program, based on the developed mathematical models for a flood management, already makes possible using it for automated calculations considering new environmental and economic requirements. Under the new conditions, it is possible to determine the parameters of various hydro systems for their successful joint work in the river basin. Further, it is planned to improve mathematical models and computer program considering the joint work with geographic information systems for a detailed assessment of flood zones and the environmental consequences of flooding.

\section{Conclusions}

This paper is one of the articles in the framework of the grant "Development of the scientific foundations and methods for reducing the risk of flooding by creating a system of flood control facilities distributed in the river basin, considering the requirements of environmental safety". In the context of climate change, as well as new energy, economic and environmental requirements, there is a need to create mathematical models and software products for automated calculations, considering the current and prospective situation in the entire river basin. 
This task has been largely solved - on the basis of the developed new mathematical models, a new computer program has been proposed for calculating the parameters and operating modes of hydro systems of various purposes, during their separate and joint operation throughout the river basin. A computer simulation was conducted for the hydro systems in the river basin in the Far Eastern region of Russia, new results were obtained considering various requirements. The computer program calculations are further used in conjunction with GIS for assessing areas of flooding and environmental damage during floods. This makes possible to reduce the risk of flooding by creating a system of flood control facilities distributed in the river basin.

The research was supported by Russian Science Foundation (grant №16-17-00050).

\section{References}

1. L. Alfieri, P. Burek, L. Feyen, G. Forzieri, Hydrol. Earth Syst. Sci., 19, 2247-2260 (2015)

2. N.W. Arnell, S.N. Gosling, Climatic Change, 134 (3), 457-474 (2016)

3. L. Alfieri, L. Feyen, P. Salamon, J. Thielen, A. Bianchi, F. Dottori, P. Burek, Nat. Hazards Earth Syst. Sci., 16, 1401-1411 (2016)

4. F. Dottori, M. Kalas, P. Salamon, A. Bianchi, L. Alfieri, L. Feyen, Nat. Hazards Earth Syst. Sci., 17, 1111-1126 (2017)

5. M. Fedorov, V. Badenko, V. Maslikov, A. Chusov, Procedia Engineer., 165, 16291636 (2016)

6. C. Donnelly, W. Greuell, J. Andersson, D. Gerten, G. Pisacane, P. Roudier, F. Ludwig, Climatic Change, 143 (1-2), 13-26 (2017)

7. A. Chusov, V. Maslikov, D. Molodtsov, O. Manukhina, Adv. Intel. Syst., 692, 10461054 (2018)

8. V. Maslak, N. Nasonkina, V. Sakhnoskaya, S. Antonenko, D. Nemova, Procedia Engineer., 117 (1), 985-994 (2015)

9. V.V. Davydov, V.I. Dudkin, N.S. Myazin, V. Yu. Rud', Instrum. Exp. Tech., 61 (1), 140-147 (2018)

10. N. Vatin, N. Lavrov, G. Loginov, MATEC Web of Conf., 73, 01006 (2016)

11. M.P. Sainov, Mag. Civ. Eng., 57, 20-33 (2015)

12. M. Tanoue, Y. Hirabayashi, H. Ikeuchi, Sci. Rep., 6, 36021 (2016)

13. D. Tarasova, A. Staritcyna, D. Nemova, K. Andreev, MATEC Web of Conf., 53, 01007 (2016)

14. V. Mushchanov, V. Sievka, A. Veshnevska, D. Nemova, Procedia Engineer., 117, 1018-1026 (2015)

15. M.P. Sainov, Mag. Civ. Eng., 64, 3-9 (2016)

16. A.I. Alhimenko, I.D. Kazunin, M.U. Nikolaevskiy, Proceedings of the International Offshore and Polar Engineering Conference, 1875-1878 (2015)

17. M. Petrichenko, N. Vatin, D. Nemova, N. Kharkov, A Staritcyna, Appl. Mech. Mater., 627, 297-303 (2014)

18. N.S. Myazin, S.E. Logunov, V.V. Davydov, V. Yu. Rud', N.M. Grebenikova, V.V. Yushkova, J. Phys.: Conf. Ser., 929 (1), 012064 (2017)

19. V.V. Davydov, N.S. Myazin, Meas. Tech., 60 (2), 183-189 (2017) 
20. N.S. Myazin, V.V. Davydov, V.V. Yushkova, T.I. Davydova, V. Yu. Rud', J. Phys.: Conf. Ser., 917 (4), 042017 (2017)

21. V.V. Davydov, N.S. Myazin, T.I. Davydova, Russian Journal of Nondestructive Testing, 53 (7), 520-529 (2017)

22. M.A. Mikhalev, Mag. Civ. Eng., 37 (2), 67-74 (2013)

23. A.D. Girgidov, Power Technol. Eng., 45 (5), 351-355 (2012)

24. M.P. Sainov, O.V. Anisimov, Mag. Civ. Eng., 68, 3-17 (2016)

25. M.P. Sainov, V.V. Lubyanov, Mag. Civ. Eng., 73, 96-112 (2017)

26. T.S. Titova, A. Longobardi, R.G. Akhtyamov, E.S. Nasyrova, Mag. Civ. Eng., 69, 3443 (2017)

27. M.P. Sainov, F.V. Kotov, Mag. Civ. Eng., 69, 44-55 (2017)

28. M.P. Sainov, A.O. Zverev, Mag. Civ. Eng., 75, 76-83 (2017)

29. M. Fedorov, V. Badenko, V. Maslikov, A. Chusov, MATEC Web of Conf. 73, 01002 (2016)

30. V. Badenko, N. Badenko, A. Nikonorov, D. Molodtsov, V. Terleev, J. Lednova, V. Maslikov, MATEC Web of Conf., 73, 03003 (2016)

31. M.P. Fedorov, V.I. Maslikov, V.L. Badenko, A.N. Chusov, D.V. Molodtsov, Power Technology and Engineering, 51 (4), 365-370 (2017)

32. R. Davydov, V. Antonov, D. Molodtsov, A. Trebukhin, Advances in Intelligent Systems and Computing, 692, 915-920 (2018) 